\title{
QUALITY AND LOCATION CHOICES UNDER \\ PRICE REgulation
}

\author{
KURT R. BREKKE \\ Department of Economics \\ Programme for Health Economics in Bergen (HEB) \\ Norwegian School of Economics \\ and Business Administration \\ kurt.brekke@nhh.no \\ ROBERT NUSCHELER \\ Wissenschaftszentrum Berlin für Sozialforschung (WZB) \\ robert@wz-berlin.de \\ Odd Rune StRaume \\ Department of Economics \\ University of Bergen \\ N-5007 Bergen, Norway \\ odd.straume@econ.uib.no
}

In a model of spatial competition, we analyze the equilibrium outcomes in markets where the product price is exogenous. Using an extended version of the Hotelling model, we assume that firms choose their locations and the quality of the product they supply. We derive the optimal price set by a welfarist regulator. If the regulator can commit to a price prior to the choice of locations, the optimal (second-best) price causes overinvestment in quality and an insufficient degree of horizontal differentiation (compared with the first-best solution) if the transportation cost of consumers is sufficiently high. Under partial commitment, where the regulator is not able to commit prior to location choices, the optimal price induces first-best quality, but horizontal differentiation is inefficiently high.

\section{INTRODUCTION}

In this paper we study the strategic interaction between horizontal differentiation and the supply of quality in markets that are subject to price regulation. Imperfect competition does not generally guarantee an optimal supply of quality or locational efficiency. This could provide a a co-editor, and two anonymous referees for very helpful comments and suggestions. 
rationale for regulation. In the present paper we characterize the optimal regulated price in markets where firms compete along both vertical and horizontal dimensions.

It is well known that the market cannot always be relied upon to supply a socially efficient level of product quality. This is illustrated within a monopoly framework in a seminal paper by Spence (1975). ${ }^{1}$ Introducing competition between firms, Ma and Burgess (1993) identify another potential inefficiency caused by the strategic interaction between quality and price competition that will generally lead to suboptimal product quality. When quality and price decisions are made sequentially, firms will underinvest in quality to dampen price competition. A regulator can then make the firms commit to a higher level of product quality by eliminating price competition.

In imperfectly competitive markets, though, an important part of the strategic interaction among firms also takes place along a spatial dimension. It is well known that the location choices of firms, interpreted in either geographical space or product space, are highly dependent on whether or not prices are regulated. For instance, Anderson and Engers (1994) show that price-taking firms will agglomerate at the market center in a spatial duopoly if demand is sufficiently inelastic, a result that corresponds with Hotelling's (1929) prediction of minimum differentiation. ${ }^{2}$ On the other hand, if firms are allowed to compete in prices they can reduce competition by locating further apart. In another seminal contribution, D'Aspremont et al. (1979) show that, under certain conditions, price competition induces the firms to locate at either extreme of the Hotelling line, a result often referred to as the "Principle of Maximum Differentiation." From a welfare point of view, it is clear that neither location at the market center nor location at the market borders is desirable.

The case of location-quality competition has received relatively little attention in the literature, and is therefore less understood. The purpose of this paper is to examine the interaction between location and quality choices made by competing firms facing a fixed product price, and to explore welfare implications and optimal regulation of prices in such markets. We do so by employing a model where two firms choose location (or specialization) of their product on the "unconstrained" Hotelling line prior to investment decisions that affect the quality of the

1. The incentive to provide quality is related to the marginal willingness to pay for quality, for the marginal consumer in the case of a profit-maximizing firm, and for the average consumer in the case of a social planner. Depending on the difference between the consumers' marginal and average valuations, the supply of quality may be higher or lower than the social optimum.

2. In a related paper, Hinloopen (2002) analyzes the location choices of firms in a priceregulated spatial duopoly where consumers' reservation prices may bind in equilibrium. 
product offered. A welfarist regulator sets the price of the product (or the third-party payment) at a stage that either precedes or immediately follows the locational decisions, depending on the level of regulatory commitment.

A prime example of where the situation analyzed in this paper applies is the health care market. In response to the peculiarities of medical services or, more generally, health goods, compensation of health care suppliers is, in most countries, set by some regulatory authority. In the absence of price as a strategic variable, health care suppliers will resort to other variables to attract patients. Considering the hospital market, the management at a hospital has (at least) two important strategic decisions to make. First, they have to decide what services or treatments the hospital should offer. For example, should they specialize in care for cardiac or oncology patients? Second, the management must decide on the quality of the services provided. This decision involves investments in medical equipment (e.g., CT scanners), contracts with highly skilled physicians, etc. Both decisions are likely not only to affect the hospital's costs, but also its demand and, in turn, the payments the hospitals receive from the regulator. Consequently, hospitals will set quality (vertical differentiation) and specialization (horizontal differentiation) strategically. ${ }^{3,4}$

Another relevant example is the market for (especially higher) education. Consider an educational market where tuition fees play a negligible role, and the funding of educational institutions is correlated with student attendances. This applies to many European countries in particular. In such markets there are essentially two different concerns that are important for a potential student's choice of educational establishment (school): the quality and the (horizontal) characteristics of the schooling offered. The quality aspect could be anything from the quality of lecturers to the range of library services, whereas the horizontal characteristics are typically related to the range and types of courses offered. It is thus reasonable to believe that schools will make strategic decisions, in terms of vertical and horizontal differentiation, in order to attract students.

Our main findings are the following: first, a higher price will increase the equilibrium level of quality, but it will also induce the firms

3. The horizontal dimension could also be interpreted in the geographical sense. Consider two hospitals providing the same quality of care. A patient would then simply consult the hospital closer to where he lives.

4. The market for prescription drugs may also serve as an example. In such markets prices are usually regulated and patients are reimbursed a substantial share of the medication expenditures. Moreover, pharmaceuticals are often vertically (e.g., "perceived" therapeutic value) and horizontally (e.g., chemical substance) differentiated, capturing both branded versus generics and branded versus branded competition. 
to locate further apart. The higher the price-cost margin, the higher the benefits, in terms of profits, of capturing a larger share of the market, and this induces the firms to compete more intensively on quality. However, firms have then an incentive to locate further apart in order to dampen quality competition.

We characterize the optimal regulatory policy under two alternative assumptions about the sequence of moves. Under full commitment, where the regulator sets a price at the outset of the game, the optimal (second-best) price causes overinvestment in quality and an insufficient degree of differentiation, compared with the first-best outcome, if the transportation cost of consumers is sufficiently high. This outcome is contrasted with the case of partial commitment, where the regulator is not able to commit to a price prior to the firms' locational decisions. In this case-which corresponds well with a geographical interpretation of firm location-optimal regulation induces first-best quality provision, but excessive differentiation.

This paper relates to the following literature: the paper by Ma and Burgess (1993) shows that price regulation reduces inefficiencies in the provision of quality in a spatial duopoly. Wolinsky (1997) extends the former study, both in terms of optimal market regime (managed competition versus regulated monopolies) and asymmetric information. However, in both studies locations are exogenous, and thus the interaction between quality and location is not investigated.

Economides (1989) considers both quality and location choices under price competition, and Bester (1998) analyzes the effect of imperfect information about quality on firms' location choices in a similar model. Price regulation, however, is not an issue in either paper.

Two other related papers applied to health care markets are Gravelle (1999) and Nuscheler (2003). In both cases, though, attention is directed toward entry of firms in a circular model, which means that the distance between firms is determined by the number of firms entering the market, so the focus of these papers is quite different from the present one in this respect. Finally, in a paper applied specifically to the hospital market, Calem and Rizzo (1995) consider the interaction between location and quality choices under the assumption that hospitals cover a fraction of their patients' transportation costs. This paper differs from ours in two important ways, though. First, they do not consider optimal regulation, which is a major issue in the present paper. Second, the very particular assumptions in their model reduce its applicability beyond hospital markets.

The remainder of the paper is organized as follows. In Section 2 we present the main ingredients of the model. In Section 3 we analyze 
the strategic relationship between quality and location choices when the firms face an exogenous product price. In Section 4 we derive the optimal regulated price and the corresponding equilibrium outcome under full commitment, whereas the case of partial commitment is analyzed in Section 5. In Section 6 we briefly discuss the impact of unequal welfare weights on the outcome of the commitment game. Finally, some concluding remarks are offered in Section 7.

\section{THE MODEL}

A unit mass of consumers is distributed uniformly on the line segment $[0,1]$. Each of two identical single-product firms, indexed by $i=1,2$, chooses a location $x_{i}$ and a quality level $q_{i} \geq 0$. In order to secure the existence of pure-strategy equilibria throughout the analysis, we make the following assumptions about the firms' choice sets in the location game: firm 1 chooses a location $x_{1} \in\left[0, \frac{1}{2}-\bar{x}\right]$, whereas firm 2 chooses $x_{2} \in\left[\frac{1}{2}+\bar{x}, 1\right]$, where $\bar{x}$ is a (small) positive number. This means that the firms cannot locate too close to each other. Both firms charge the same exogenous (regulated) price $p$ for the product. ${ }^{5}$

Each consumer demands one unit of the good. The utility derived by a consumer located at $z$ from getting a unit of the product from firm $i$ is given by

$U\left(z, x_{i}, q_{i}\right)=v+q_{i}-t\left(z-x_{i}\right)^{2}-p$.

This utility specification implies that consumers always prefer higher quality. We assume that the gross utility, $v+q_{i}$, is always large enough for the whole market to be covered, even at $q_{i}=0$. Given that $v$ is assumed to be equal for all consumers, and that the two firms charge the same price, the location $\bar{z}$ of the consumer who is indifferent between buying the product from either firm is the solution to

$q_{1}-t\left(\bar{z}-x_{1}\right)^{2}=q_{2}-t\left(x_{2}-\bar{z}\right)^{2}$

and is given by

$\bar{z}=\frac{1}{2}\left(x_{1}+x_{2}\right)+\frac{q_{1}-q_{2}}{2 t\left(x_{2}-x_{1}\right)}$.

5. Alternatively, we can think of this as the payment transferred from a third party (e.g., an insurer or a governmental agency) to the firms. The analytical exposition is simplified by considering a single price for both firms. Due to the symmetric nature of the model, the equilibrium outcome is obviously not affected by this simplification. 
Let $y_{i}$ be the total demand facing firm $i$. With a uniform distribution of consumers, the distribution of market shares between the two firms is given by $y_{1}=\bar{z}$ and $y_{2}=1-\bar{z}$.

The marginal cost of production, denoted $c$, is assumed to be constant and independent of locations. The cost of achieving a quality level $q_{i}$ is given by a cost function $K\left(q_{i}\right){ }^{6}$ We make the following assumptions on $K$ :

(1) $K^{\prime}(\cdot)>0, K^{\prime \prime}(\cdot)>0, K(0)=K^{\prime}(0)=0$.

(2) $\left[K^{\prime \prime}(\cdot)\right]^{2}-K^{\prime}(\cdot) K^{\prime \prime \prime}(\cdot) \geq 0$.

The assumptions in (1) are standard. Assumption (2) secures equilibrium existence in the location game. This assumption holds for any function of the type $K(q)=k q^{n} ; k>0, n>1$.

The profit of firm $i$ is thus ${ }^{7}$

$\pi_{i}=(p-c) y_{i}-K\left(q_{i}\right), \quad i=1,2$.

For the main part of the analysis, we consider the following threestage game:

- Stage 1: The regulator sets a price $p$.

- Stage 2: The firms simultaneously choose locations $x_{1}$ and $x_{2}$.

- Stage 3: The firms simultaneously choose the quality levels $q_{1}$ and $q_{2}$.

This sequence of moves relies on the assumption that the regulator is able to precommit to a regulatory policy. This assumption could be justified by a reputation argument. Commitment could also be obtained by creating institutional mechanisms that make it costly, or otherwise difficult, to change the regulated price. In Section 5 we will contrast the results derived from the above specified game with the case of partial commitment, where the regulator is not able to commit to a price prior to location decisions. In either case we assume that choice of location is more of a long-term decision than choice of quality is. ${ }^{8}$

6. The assumption that the firms' costs are separable in quality and quantity implies that quality has the characteristics of a public good for the consumers. This is a widely used assumption in the literature (see, e.g., Economides, 1989, 1993; Calem and Rizzo, 1995; Lyon, 1999; Gravelle and Masiero, 2000; Barros and Martinez-Giralt, 2002).

7. Note that price regulation in this setting is equivalent to regulating firms' mark-ups.

8. When considering simultaneous location and quality decisions, then, by the same argument as in Gabszewicz and Thisse (1992, pp. 291-292), no equilibrium in purestrategies exists. As we concentrate on pure-strategy equilibria throughout the paper we neglect that particular timing. 


\section{EQUILIBRIUM QUALITIES AND LOCATIONS}

We start out by deriving the Nash equilibrium outcome for a given price $p$, in order to analyze how the firms' choices of location and quality are determined by the regulated price. As usual, the game is solved by backward induction.

\subsection{QuALITY COMPETITION}

We look for an equilibrium in pure strategies in the quality subgame. ${ }^{9}$ For a given pair of locations $\left(x_{1}, x_{2}\right)$ and a given price $p$, the first-order condition for an optimal quality level $q_{i}^{*}$ is given by ${ }^{10}$

$$
\frac{p-c}{2 t \Delta}-K^{\prime}\left(q_{i}^{*}\right)=0
$$

where $\Delta:=\left(x_{2}-x_{1}\right) \in[2 \bar{x}, 1]$.

The first observation to be made is that the equilibrium levels of quality depend only on relative locations, not on absolute locations. In other words, only the distance between the firms, $\Delta$, matters. Thus, the firms will always invest equally much in quality, even if they are asymmetrically located. This is due to the absence of price competition. When prices are exogenous, there is only a market share effect of quality investments. By increasing the level of quality, firm $i$ is able to capture a larger share of the market by "pushing" the indifferent consumer in the direction of the rival firm. Because consumers are uniformly distributed, this effect does not depend on absolute locations.

The comparative static results are easily obtained by total differentiation of the first-order condition, yielding

$$
\begin{aligned}
& \frac{\partial q_{i}^{*}(\Delta ; \cdot)}{\partial \Delta}=-\frac{(p-c)}{2 t \Delta^{2} K^{\prime \prime}(\cdot)}<0, \\
& \frac{\partial q_{i}^{*}(\Delta ; \cdot)}{\partial t}=-\frac{(p-c)}{2 t^{2} \Delta K^{\prime \prime}(\cdot)}<0, \\
& \frac{\partial q_{i}^{*}(\Delta ; \cdot)}{\partial p}=\frac{1}{2 t \Delta K^{\prime \prime}(\cdot)}>0 .
\end{aligned}
$$

The optimal level of quality decreases in the distance between the firms. This is due to the convexity of transportation costs. ${ }^{11}$ From the

9. The concept of mixed strategies does not seem to make much sense in the context of firms' quality investment decisions, so we disregard this possibility by assumption.

10 . The second-order condition is satisfied, since $K^{\prime \prime}(\cdot)>0$.

11. It is straightforward to show that if transportation costs were linear, firms' quality choice and, thus, equilibrium quality would be independent of locations (or distance), precluding meaningful nonprice competition. 
viewpoint of either firm, the further apart the firms are located, the smaller the market share captured by a marginal increase in quality. Thus, differentiation softens quality competition. A similar kind of argument applies for the negative relationship between $q_{i}^{*}$ and $t$. The more costly it is for consumers to "travel," the smaller the benefits, in terms of increased market shares, for either firm of investing in quality improvements. This implies that the local monopoly power of firms increases as $t$ increases. ${ }^{12}$ Finally, the optimal level of quality increases with the price level, $p$. With the assumption of constant marginal costs, this result is quite intuitive. The higher the price-cost margin, the higher the benefits, in terms of profits, of capturing a larger share of the market. Consequently, the stronger is the incentive to increase the level of quality. Indeed, a positive price-cost margin is a necessary condition for the firms to make quality investments at all.

In order to ensure the existence of equilibrium in the quality subgame, it remains to be ensured that firms earn nonnegative profits for all possible locations. For a given pair of locations $\left(x_{1}, x_{2}\right)$, equilibrium profits for firm $i$ are given by

$\pi_{i}\left(x_{1}, x_{2}, p, q_{i}^{*}(\Delta ; \cdot)\right)=\frac{1}{2}(p-c)\left(x_{1}+x_{2}\right)-K\left(q_{i}^{*}(\Delta ; \cdot)\right)$,

from which we can derive

$$
\begin{gathered}
\frac{\partial \pi_{i}\left(x_{1}, x_{2}, p, q_{i}^{*}(\Delta ; \cdot)\right)}{\partial p}=\frac{1}{2}\left(x_{1}+x_{2}\right)-\frac{K^{\prime}(\cdot)}{K^{\prime \prime}(\cdot)} \frac{1}{2 t \Delta}, \\
\frac{\partial^{2} \pi_{i}\left(x_{1}, x_{2}, p, q_{i}^{*}(\Delta ; \cdot)\right)}{\partial p^{2}}=-\left[\frac{\left[K^{\prime \prime}(\cdot)\right]^{2}-K^{\prime}(\cdot) K^{\prime \prime \prime}(\cdot)}{4 t^{2} \Delta^{2}\left[K^{\prime \prime}(\cdot)\right]^{3}}\right] .
\end{gathered}
$$

We see that $\partial^{2} \pi_{i} / \partial p^{2}<0$. Furthermore, using our assumptions on $K(\cdot)$, it is straightforward to show that $\lim _{p \rightarrow c} \pi_{i}=0, \lim _{p \rightarrow \infty} \pi_{i}<0$, and $\lim _{p \rightarrow c}\left(\partial \pi_{i} / \partial p\right)>0$, implying that there exists a $\bar{p}>c$ such that $\pi_{i}\left(x_{1}, x_{2}, p, q_{i}^{*}(\Delta ; \cdot)\right) \geq 0$ if $p \in[c, \bar{p}]$. Thus, equilibrium existence requires an upper bound $\bar{p}$ on the regulated price.

\subsection{LOCATION CHOICE}

At stage 2 of the game, the firms simultaneously choose their locations, anticipating the quality pair $\left(q_{1}^{*}(\Delta ; \cdot), q_{2}^{*}\left(\Delta_{;} \cdot\right)\right)$ at the subsequent stage of the game. Using (5) and (4), the first-order conditions for an interior solution in the location game are given by

12. Note that if we use the product space interpretation of horizontal differentiation, an increase in transportation costs can be interpreted as more heterogeneous consumer preferences. 


$$
\begin{aligned}
& \frac{\partial \pi_{1}}{\partial x_{1}}=\frac{1}{2}(p-c)\left(1-\frac{K^{\prime}(\cdot)}{K^{\prime \prime}(\cdot)} \frac{1}{t \Delta^{2}}\right)=0, \\
& \frac{\partial \pi_{2}}{\partial x_{2}}=-\frac{1}{2}(p-c)\left(1-\frac{K^{\prime}(\cdot)}{K^{\prime \prime}(\cdot)} \frac{1}{t \Delta^{2}}\right)=0 .
\end{aligned}
$$

We see that the first-order conditions are met for a unique distance, $\Delta^{*}$, between the firms. The interior solution is thus given by

$$
\frac{K^{\prime}(\cdot)}{K^{\prime \prime}(\cdot)}=t\left(\Delta^{*}\right)^{2}
$$

Assuming a symmetric equilibrium, there are two possible corner solutions, given by $\left(x_{1}^{*}, x_{2}^{*}\right)=\left(\frac{1}{2}-\bar{x}, \frac{1}{2}+\bar{x}\right)$ and $\left(x_{1}^{*}, x_{2}^{*}\right)=(0,1)$, respectively. It follows from (9) and (10) that the location equilibrium is a corner solution with minimal differentiation if

$$
\frac{K^{\prime}(\cdot)}{K^{\prime \prime}(\cdot)} \leq t(2 \bar{x})^{2}
$$

and the corner solution with maximal differentiation if

$\frac{K^{\prime}(\cdot)}{K^{\prime \prime}(\cdot)} \geq t$.

The second-order conditions are given by

$\frac{\partial^{2} \pi_{i}}{\partial x_{i}^{2}}=-(p-c)\left(\Omega(\cdot) \frac{(p-c)}{4 t^{2} \Delta^{4}}+\frac{K^{\prime}(\cdot)}{K^{\prime \prime}(\cdot)} \frac{1}{t \Delta^{3}}\right), \quad i=1,2$,

where $\Omega(\cdot):=\frac{\left[K^{\prime \prime}(\cdot)\right]^{2}-K^{\prime}(\cdot) K^{\prime \prime \prime}(\cdot)}{\left[K^{\prime \prime}(\cdot)\right]^{3}} \geq 0$. Thus, with our assumptions on $K(\cdot)$, the second-order conditions are always satisfied.

An important feature of the location-quality equilibrium is that the presence of quality competition introduces a centrifugal force in the location game. In the absence of quality competition, we know that exogenous prices cause the firms to choose minimal differentiation. However, the possibility of quality-enhancing investments introduces a degree of competition that the firms are able partly to avoid by locating further away from each other. From (11) we see that the strength of this effect is partly determined by the convexity of the investment cost function. The less convex the investment cost function is-that is, the higher $\frac{K^{\prime}(\cdot)}{K^{\prime \prime}(\cdot)}$ is - the stronger are the incentives for quality competition for given locations. This increases the firms' incentives to avoid quality competition by locating further apart.

The comparative static effects of $p$ and $t$ on the equilibrium distance between firms in the interior solution is obtained by total differentiation of (11), yielding 


$$
\begin{aligned}
& \frac{\partial \Delta^{*}(\cdot)}{\partial p}=\frac{\Omega(\cdot) \Delta^{*}}{\Omega(\cdot)(p-c)+4\left(\Delta^{*}\right)^{3} t^{2}}>0, \\
& \frac{\partial \Delta^{*}(\cdot)}{\partial t}=-\frac{\Omega(\cdot)(p-c)+2\left(\Delta^{*}\right)^{3} t^{2}}{t} \frac{\Delta^{*}}{\Omega(\cdot)(p-c)+4\left(\Delta^{*}\right)^{3} t^{2}}<0 .
\end{aligned}
$$

The comparative statics results for the equilibrium levels of quality, when location decisions are endogenized, are found by totally differentiating (5) and using (14) and (15), yielding ${ }^{13}$

$$
\begin{aligned}
& \frac{\partial q^{*}(\cdot)}{\partial p}=\frac{2 t\left(\Delta^{*}\right)^{2}}{\Omega(\cdot)(p-c)+4\left(\Delta^{*}\right)^{3} t^{2}} \frac{1}{K^{\prime \prime}(\cdot)}>0, \\
& \frac{\partial q^{*}(\cdot)}{\partial t}=-\frac{(p-c)\left(\Delta^{*}\right)^{2}}{\Omega(\cdot)(p-c)+4\left(\Delta^{*}\right)^{3} t^{2}} \frac{1}{K^{\prime \prime}(\cdot)}<0 .
\end{aligned}
$$

The following proposition summarizes the results.

Proposition 1: Both the equilibrium levels of quality and the equilibrium distance between the firms decrease in $\mathrm{t}$, and increase in $p$.

From the discussion in Section 3.1, we know that an increase in the price level will, ceteris paribus, induce the firms to increase quality, implying that the competition between the firms intensifies. The firms have incentives to dampen this effect, though, by locating further apart. However, Proposition 1 confirms that the latter (indirect) effect is smaller than the former (direct) effect. Consequently, an increase in the product price leads to increased quality in equilibrium. There are similar mechanisms at work for the comparative statics results regarding the transportation cost parameter $t$. When locations are endogenous, the direct negative effect on quality from an increase in $t$ is partly mitigated by a smaller distance between the firms in equilibrium, resulting in stronger incentives for quality investments. The overall effect, though, is a decrease in the equilibrium levels of quality.

\section{Optimal Regulation Under FULL COMMITMENT}

In this section we analyze how a regulator should optimally set the price in this particular market. The desirability of price regulation can arise for several reasons. Importantly, in this type of model, allowing for price competition generally leads to both suboptimal equilibrium

13. To save notation, we use the notational shorthand $q^{*}(\cdot):=q^{*}\left(\Delta^{*}(\cdot) ; \cdot\right)$ to denote equilibrium quality when locations are endogenous. This convention is used throughout the paper. 
levels of quality and socially inefficient locations, due to the strategic interaction between the firms. This could, in itself, create a potential role for regulation. However, we also want to treat this model as a depiction of markets in which price regulation is viewed as desirable due to, for example, distributional considerations, like in markets for healthcare or education.

The vertical and horizontal dimensions of the product (quality and locations) are assumed to be noncontractible, leaving the product price as the only regulatory instrument. ${ }^{14}$ We assume that the regulator maximizes the sum of consumers' and producers' surpluses. ${ }^{15}$ We confine the analysis to the case of symmetric equilibria. Imposing symmetry, and easing notation by writing $q_{i}=q$, social welfare is given by

$W=v+q-\frac{t}{12}+\frac{t}{4} \Delta(1-\Delta)-2 K(q)-c$.

\subsection{ThE FIRST-BEST SOLUTION}

For comparative purposes, we start out by considering the socially optimal first-best solution. With the assumption of unit demand, there is no efficiency loss associated with a price in excess of marginal costs, so that the only relevant variables are locations and quality. The first-order conditions for a first-best solution are given by ${ }^{16}$

$$
\begin{aligned}
& \frac{\partial W}{\partial \Delta}=\frac{t}{4}(1-2 \Delta)=0 \\
& \frac{\partial W}{\partial q}=1-2 K^{\prime}(\cdot)=0 .
\end{aligned}
$$

The first-best solution is characterized by a pair of locations that minimize total transportation costs for consumers. When consumers are uniformly distributed on the line segment $[0,1]$, this pair of locations is given by $\left(\frac{1}{4}, \frac{3}{4}\right)$, which implies $\Delta=\frac{1}{2}$. The first-best solution also requires a quality level that equates marginal revenues and marginal costs.

14. Due to measurement problems related to vertical and horizontal differentiation, these variables will typically be nonverifiable in a contractual sense.

15. If we interpret the model in the context of markets with third-party payers (typically markets for healthcare and education), this particular specification of the welfare function relies implicitly on the assumption that the third party (i.e., the regulator) is able to raise the necessary funds in a nondistortionary manner.

16. The second-order conditions are satisfied, since $\frac{\partial^{2} W}{\partial \Delta^{2}}=-\frac{1}{2} t<0, \frac{\partial^{2} W}{\partial q^{2}}=-2 K^{\prime \prime}(\cdot)<$ 0 , and $\frac{\partial^{2} W}{\partial \Delta \partial q}=0$. 


\subsection{THE SECOND-BEST SOLUTION}

When the regulator is not able to control locations and quality directly but only indirectly through the price level, the equilibrium outcome is generally expected to fall short of the first-best solution. ${ }^{17}$ Before scrutinizing whether this is indeed the case, we will first consider the case of exogenous locations.

\subsubsection{EXOGENOUS LOCATIONS}

For exogenous (symmetric) locations, the regulator faces the following problem:

$$
\max _{p \in[c, \bar{p}]} W=v+q^{*}(\Delta ; \cdot)-\frac{t}{12}+\frac{t}{4} \Delta(1-\Delta)-2 K\left(q^{*}(\Delta ; \cdot)\right)-c .
$$

Assuming an interior solution, the first-order condition for an optimal price is given by ${ }^{18}$

$$
\frac{\partial W}{\partial p}=\frac{\partial q^{*}(\Delta ; \cdot)}{\partial p}\left[1-2 K^{\prime}(\cdot)\right]=0 .
$$

Comparing with (20), we see that the optimal solution yields first-best quality provision, as expected. The socially optimal levels of quality can be achieved at all possible locations by imposing the appropriate price level. Substituting $K^{\prime}(\cdot)=\frac{1}{2}$ into the first-order condition for the firms' optimal quality investments, (5), we find that this price is given by

$p^{*}(\Delta ; \cdot)=c+\Delta t$.

An almost trivial, yet important, observation is that optimal price regulation implies a price in excess of marginal production costs. A positive mark-up is necessary in order to induce the firms to undertake quality investments. More interesting, though, is the following result.

Proposition 2: With exogenous symmetric locations, the optimal regulated price is an increasing function of the distance between the firms.

Proof. Follows immediately from (22).

The intuition is relatively straightforward. Although the distance between the firms influences the incentives for quality investments, the socially optimal level of product quality is independent of locations. For a given price, a larger distance between the firms reduces the intensity

17. Note that if the regulator could set location-specific prices, then the problem becomes trivial in the sense that the first-best is always implementable.

18. The second-order condition is satisfied, since $\frac{\partial^{2} W\left(p^{*}\right)}{\partial p^{2}}=-2\left(\frac{\partial q^{*}(\Delta ; \cdot)}{\partial p}\right)^{2} K^{\prime \prime}(\cdot)<0$. 
of quality competition, and thus the equilibrium levels of quality. The regulator can stimulate quality investments by increasing the price, which increases the marginal revenue of such investments. Thus, the further apart the firms are located, the higher is the price that is required to provide the firms with sufficient incentives to invest at the socially optimal quality level.

\subsubsection{ENDOGENOUS LOCATIONS}

If the firms are able to choose their locations, the regulator must take into account how the regulated price affects not only quality but also the choice of locations. From Proposition 1 we know that a higher price induces higher quality and more horizontal differentiation. For endogenous locations, the regulator faces the following problem:

$$
\max _{p \in[c, \bar{p}]} W=v+q^{*}(\cdot)-\frac{t}{12}+\frac{t}{4} \Delta^{*}(\cdot)\left[1-\Delta^{*}(\cdot)\right]-2 K\left(q^{*}(\cdot)\right)-c .
$$

Again, assuming an interior solution, the first-order condition for an optimal price $p^{*}$ is given by ${ }^{19}$

$$
\frac{\partial W}{\partial p}=\frac{\partial q^{*}(\cdot)}{\partial p}\left[1-2 K^{\prime}(\cdot)\right]+\frac{t}{4} \frac{\partial \Delta^{*}(\cdot)}{\partial p}\left[1-2 \Delta^{*}(\cdot)\right]=0 .
$$

The first-order condition for the second-best price is easily interpretable: the first term represents the marginal social (net) benefit of improved quality, whereas the second term is the marginal social benefit of increased horizontal differentiation. The regulator has to weigh these considerations against each other, and social welfare is maximized at a price for which the sum of these two net marginal benefits equates zero. Due to the monotonicity of $q^{*}(\cdot)$ and $\Delta^{*}(\cdot)$, the first-best outcome is achieved for a unique value of the transportation cost parameter. Let this value be denoted by $\hat{t}$. From (23) we see that in general, for $t \neq \hat{t}$, second-best regulation provides either too much quality provision and an insufficient degree of differentiation, or vice versa. Assuming that $p^{*}(\hat{t})<\bar{p}$, the efficiency properties of the second-best solution can be more accurately characterized as follows.

Proposition 3: When locations are endogenous, the first-best outcome is achieved only if $t=\hat{t}$. For $t \neq \hat{t}$, the second-best outcome is characterized by (i) underinvestment in quality and too much differentiation if

19. We assume that the second-order condition is satisfied. This condition is given by $\frac{\partial^{2} W}{\partial p^{2}}=\frac{\partial^{2} q^{*}(\cdot)}{\partial p^{2}}\left[1-2 K^{\prime}(\cdot)\right]+\frac{t}{4} \frac{\partial^{2} \Delta^{*}(\cdot)}{\partial p^{2}}\left[1-2 \Delta^{*}(\cdot)\right]-2\left[K^{\prime \prime}(\cdot)\left(\frac{\partial q^{*}(\cdot)}{\partial p}\right)^{2}+\frac{t}{4}\left(\frac{\partial \Delta^{*}(\cdot)}{\partial p}\right)^{2}\right]<0$. 
$t<\hat{t}$, and (ii) overinvestment in quality and insufficient differentiation if $t>\hat{t}$.

Proof. On general form, the first-order condition for an optimal price $p^{*}$ can be written as

$$
\frac{\partial W\left(\Delta^{*}(\cdot), q^{*}(\cdot)\right)}{\partial p}=\frac{\partial W(\cdot)}{\partial \Delta} \frac{\Delta^{*}(\cdot)}{\partial p}+\frac{\partial W(\cdot)}{\partial q} \frac{\partial q^{*}(\cdot)}{\partial p}=0 .
$$

Let $\hat{p}(t)$ be the price that induces first-best locations for any value of $t$, that is, $\Delta^{*}(\hat{p}(t), t)=\frac{1}{2}$. Equilibrium quality provision at this price is then given by $q^{*}(\hat{p}(t), t)$. The relationship between $q^{*}$ and $t$-at the price $\hat{p}$-is given by

$$
\frac{d q^{*}(\hat{p}(t), t)}{d t}=\frac{\partial q^{*}(\hat{p}(t), t)}{\partial p} \frac{d \hat{p}(t)}{d t}+\frac{\partial q^{*}(\hat{p}(t), t)}{\partial t} .
$$

In order to determine the sign of $\frac{d q^{*}(\hat{p}(t), t)}{d t}$, we need to find an expression for $\frac{d \hat{p}(t)}{d t}$. This can be found from the first-order condition for the firms' optimal location choice at the price $\hat{p}$. From (11) this is given by $\frac{K^{\prime}\left(q^{*}(\hat{p}, t)\right)}{K^{\prime \prime}\left(q^{*}(\hat{p}, t)\right)}=\frac{1}{4} t$

By total differentiation, and the use of (16) and (17), we can derive

$$
\frac{d \hat{p}}{d t}=\frac{4 \Omega(\cdot)(p-c)+t^{2}}{4 t \Omega(\cdot)} .
$$

From (25) we can now derive $\frac{d q^{*}(\hat{p}(t), t)}{d t}=\frac{1}{4 \Omega(\cdot) K^{\prime \prime}(\cdot)}>0$.

Thus, there exists a $\hat{t}$ such that $q^{*}(\hat{p}(t), t)$ is below (above) the first-best level of quality provision if $t<(>) \hat{t}$.

Now consider the case of $t>\hat{t}$. Because $q^{*}(\hat{p}(t), t)$ is above firstbest, this means that $\frac{\partial W(\cdot)}{\partial q}<0$ at $q^{*}(\hat{p}(t), t)$. From Proposition 1 we also know that $\frac{\partial \Delta^{*}(\cdot)}{\partial p}>0$ and $\frac{\partial q^{*}(\cdot)}{\partial p}>0$. Furthermore, at $\Delta=\frac{1}{2}$ it follows that $\frac{\partial W(\cdot)}{\partial \Delta}=0$. Thus, we have that

$$
\frac{\partial W(\cdot)}{\partial \Delta} \frac{\Delta^{*}(\cdot)}{\partial p}+\frac{\partial W(\cdot)}{\partial q} \frac{\partial q^{*}(\cdot)}{\partial p}<0 \quad \text { at } p=\hat{p} .
$$

Consequently, no $p$ can ensure that $\frac{\partial W(\cdot)}{\partial \Delta}=\frac{\partial W(\cdot)}{\partial q}=0$. For the first-order condition to hold, the first term in (27) must be positive. This can only be achieved by setting $p<\hat{p}$, which yields $\Delta^{*}(\cdot)<\frac{1}{2}$ and implies that 
$\frac{\partial W(\cdot)}{\partial \Delta}>0$. The second-best outcome is thus achieved by setting a price $p^{*}$, where $\frac{\partial W(\cdot)}{\partial \Delta}>0$ and $\frac{\partial W(\cdot)}{\partial q}<0$ at the equilibrium pair $\left(\Delta^{*}\left(p^{*}\right), q^{*}\left(p^{*}\right)\right)$, implying $\Delta^{*}\left(p^{*}\right)<\frac{1}{2}$ and $q^{*}\left(p^{*}\right)$ above first-best. By symmetry, the opposite result applies for $t<\hat{t}$, and the first-best outcome is only achieved at $t=\hat{t}$.

In general, first-best locations can only be achieved at the cost of a suboptimal level of quality from a social welfare viewpoint, and vice versa. Consequently, the regulator faces a trade-off between quality provision and horizontal differentiation in implementing the secondbest solution. Proposition 3 states that if it is sufficiently costly for consumers to "travel" to a less-than-ideal location, then the secondbest solution is characterized by too much quality and insufficient differentiation. For a sufficiently low value of $t$, the opposite result applies.

The intuition for this result is related to the nature of the firms' responses-in terms of both quality investments and relocations-to changes in the regulated price. A price increase will induce the firms to invest in a higher level of quality, and, as a response to increased quality competition, the firms will also choose to differentiate more horizontally, in order to dampen competition. We can call this the "competition effect" and "centrifugal effect," respectively. The characteristics of the secondbest equilibrium depend on the relative strength of these two effects. If $t$ is high (above $\hat{t}$ ), then the "centrifugal effect" is relatively weak, because it only takes a small degree of horizontal differentiation in order to dampen quality competition considerably. Consequently, the price level necessary to induce first-best locations is so high that it provides incentives for overinvestment in quality. The regulator can then do better by balancing the considerations for quality provision and horizontal differentiation at a lower price, which yields both overinvestment in quality and an insufficient degree of differentiation. The opposite logic applies for $t<\hat{t}$.

\section{OPtimal Regulation Under PaRtial COMMITMENT}

So far we have assumed that the regulator is able to commit to a particular regulatory regime at the beginning of the game, before the firms make their decisions. However, in some circumstances (e.g., in the absence of long-term contracts), this may not be the most plausible assumption. This is particularly the case if we interpret location in the geographical space, since the physical location of a firm in most cases is a decision for the very long term. When full commitment is not possible 
for the regulator, we may suspect that the equilibrium outcome will be quite different and perhaps less desirable from a welfare point of view.

In this section we focus on the case of partial commitment, where the regulator is not able to commit to a price before firms decide on locations. Thus, the following game is considered

- Stage 1: The firms simultaneously choose locations $x_{1}$ and $x_{2}$.

- Stage 2: The regulator sets a price $p$.

- Stage 3: The firms simultaneously choose the quality levels $q_{1}$ and $q_{2}$.

From the discussion in Section 4 we know that the regulator in this case will set a price that induces a socially optimal supply of quality. This price is given by (22), with the corresponding equilibrium quality level given by (20). ${ }^{20}$

Now, at the first stage of the game, each firm simultaneously chooses its location, anticipating the optimal regulated price. When location decisions are made prior to price setting, the firms must take into account not only how location decisions affect the intensity of quality competition, but also how the regulated price is influenced. The following result obtains.

Proposition 4: Under partial commitment, the second-best price regulation induces first-best quality provision and maximal horizontal differentiation.

Proof. For any pair of locations, the regulator will set a price that induces first-best quality levels. From (22), we know that this price is given by $p^{*}(\Delta ; \cdot)=c+\Delta t$. At stage 1 , the firms' profit functions are thus given by

$$
\begin{aligned}
& \pi_{1}\left(x_{1}, x_{2}\right)=\frac{1}{2} t\left(x_{2}^{2}-x_{1}^{2}\right)-K\left(q_{1}\right), \\
& \pi_{2}\left(x_{1}, x_{2}\right)=\left(x_{2}-x_{1}\right) t-\frac{1}{2} t\left(x_{2}^{2}-x_{1}^{2}\right)-K\left(q_{2}\right) .
\end{aligned}
$$

Because quality levels are fixed at the first-best level, and $q_{1}=q_{2}$, the first-order conditions for the firms' location choices are given by $\partial \pi_{1} / \partial x_{1}=-t x_{1}$ and $\partial \pi_{2} / \partial x_{2}=t\left(1-x_{2}\right)$, which implies that there is a unique equilibrium where the firms choose locations $x_{1}=0$ and $x_{2}=1$.

Because the regulator is able to set a price that induces first-best quality for all possible locations, the firms' location choices have no

20. Note that with this sequence of moves, we cannot impose symmetry ex ante in the welfare maximization problem. However, since the firms' quality choices depend only on the distance between the firms, (22) yields first-best quality provision for all possible location pairs. 
longer any effect on the intensity of quality competition when prices can be adjusted after these choices have been made. Thus, location choices are now only determined by the effects on revenues. As before, a firm can, ceteris paribus, steal market shares by relocating in the direction of the competitor. However, closer locations also mean that the regulator will reduce the price in order to dampen quality competition and thus keep the supply of quality at the first-best level. Obviously, this reduces the revenue gain of locating closer to the competitor. Thus, in contrast to the case of full commitment, the incentives to differentiate horizontally are not caused by a desire to avoid fierce head-on quality competition. Horizontal differentiation is rather a strategy for firms to achieve a higher regulated price, since the optimal price increases in distance. In fact, Proposition 4 shows that optimal regulation under partial commitment yields maximal differentiation, implying that the degree of horizontal differentiation is inefficiently high, compared with the first-best outcome.

Even if full regulatory commitment is not possible, regulation is still socially beneficial because the supply of quality is more efficient. However, social welfare under partial commitment will be (weakly) lower than under full commitment. The reason is straightforward: under full commitment, the regulator can always pick the same policy as under partial commitment. The regulator's ability to trade off quality benefits against locational benefits enables her to improve social welfare.

\section{EXTENSION: UNEQUAL WEIGHTS ON CONSUMERS' AND PRODUCERS' SURPLUS}

So far we have assumed that the regulator places equal weights on consumers' and producers' surplus. However, in several industries this may not be the most appropriate assumption. For instance, in health care markets the regulator (or third-party payer) may place a larger weight on patients' welfare than on providers' profits when setting the optimal price. A welfare function encompassing such considerations is, assuming symmetry, the following:

$W=\int_{0}^{1} U(z, q, \Delta) d z+\alpha\left(\pi_{1}+\pi_{2}\right), \quad$ where $0<\alpha<1$,

which leads to the following modification of (18):

$W=v+q-\frac{t}{12}+\frac{t}{4} \Delta(1-\Delta)-p(1-\alpha)-\alpha(c+2 K(q))$.

There are two interesting observations we can make from (28). First, we see that a lower weight on profits relative to consumers' surplus, 
implies less concern for the firms' production and quality costs. Second, the price now enters the welfare function directly. This is because $\$ 1$ in the consumers' (or regulator's) hand is of larger value than $\$ 1$ in the firms' hand, implying that the absolute size of the regulated price now matters.

Considering the first-best solution, it is straightforward to show that this requires locations at the quartiles, as before. However, firstbest quality provision is now higher, as the marginal social (net) benefit of quality improvements is inversely related to $\alpha$. The first-best supply of quality is now given by $K^{\prime}(\cdot)=\frac{1}{2 \alpha}$.

In a second-best world, a lower weight on profits relative to consumers' surplus complicates matters. In fact, when the price is the only instrument to implement optimal quality and location, the regulator faces a trade-off between inducing high quality and at the same time keep prices low. To make this clear, consider the full commitment game analyzed in Sections 3 and 4. The regulator's problem is now to maximize (28) with respect to $p$, anticipating the firms' responses in terms of quality and location choices, as defined by (5) and (11). This gives us the following first-order condition:

$$
\frac{\partial W}{\partial p}=\frac{\partial q^{*}(\cdot)}{\partial p}\left[1-\alpha 2 K^{\prime}(\cdot)\right]+\frac{t}{4} \frac{\partial \Delta^{*}(\cdot)}{\partial p}\left[1-2 \Delta^{*}(\cdot)\right]-(1-\alpha)=0 .
$$

Let us first consider the most extreme case where the regulator places no weight on profits, $\alpha=0$. As the regulator is not concerned about the costs of quality provision, she may be tempted to increase the price (above the second-best price at $\alpha=1$ ) in order to improve quality. But, although there are no quality costs to offset gains from quality provision, increasing the price may come at a cost. First, there is a direct welfare loss from price increases $(\alpha<1)$. Second, a price increase also affects the degree of horizontal differentiation. The social desirability of the latter effect depends on whether there initially was too much or too little horizontal differentiation. ${ }^{21}$ The impact of $\alpha$ on the secondbest outcome is thus generally ambiguous. However, it can be shown that $\left.\frac{\partial W}{\partial p}\right|_{\alpha=1}>\left.\frac{\partial W}{\partial p}\right|_{0<\alpha<1}$ if $\frac{\partial q^{*}(.)}{\partial p} 2 K^{\prime}()<$.1 . If marginal quality costs are sufficiently small and if the equilibrium level of quality is sufficiently unresponsive to price changes, then the optimal regulated price is lower if the regulator is more concerned about consumers' surplus than about the profits of the firms, that is, $\left.p^{*}\right|_{0<\alpha<1}<\left.p^{*}\right|_{\alpha=1}$. In this case, a social planner acting (more) on behalf of consumers induces lower quality and

21. Note that the second-best optimum may now involve both insufficient quality provision and insufficient horizontal differentiation. 
less product differentiation in equilibrium than a social planner without any distributional concerns.

\section{CONCLUdiNg REMARKS}

The markets for medical care and (higher) education are examples where prices are often not feasible means of competition. When there is no possibility of competing in prices, firms will resort to other variables to increase market shares. One obvious dimension is the quality of the product offered (e.g., medical care or schooling). In addition to quality competition, or vertical product differentiation, there may also be horizontal differentiation. The latter may refer to either product differentiation (specialization) or the physical locations of firms.

In this paper we have analyzed, using a spatial duopoly model, the strategic interaction between firms that first determine the horizontal characteristics of their goods and then compete in quality. When products are close substitutes, quality competition will be intense. The main feature of our model is that firms can dampen quality competition by making their products less substitutable. The degree of horizontal differentiation is thus determined by the intensity of quality competition, which in turn is determined by the firms' price-cost margins and by transportation and investment costs.

Like in most sequential games, the regulator's commitment power is crucial for the outcome of the game. We analyzed two versions of the basic model, namely, full and partial commitment. With full commitment, the regulator sets the price prior to location and quality decisions. The resulting second-best solution optimally trades off vertical and horizontal differentiation incentives. As there are two regulatory goals and only one regulatory variable, the second-best solution will, in general, fall short of the first-best optimum. We found that there will be insufficient quality provision but too much differentiation when quality competition is intense (i.e., when transportation costs are low).

In cases where the regulator fails to obtain full commitment power, firms anticipate the regulators' incentive to change the price in the course of the game. We considered the case where the price is set after location decisions have been made but prior to quality investments. As the regulator is then only concerned with quality, efficient investment decisions will be implemented. However, this leads firms to "game" the regulator. The price necessary to induce efficient quality provision increases in the degree of horizontal differentiation, as the higher price must compensate for relaxed quality competition. Thus, with only partial commitment power at the hand of the regulator, we showed 
that this always results in excessive horizontal differentiation, from the viewpoint of social welfare.

Finally, some remarks should be made about a couple of the fundamental assumptions on which the analysis rests. A key assumption is the noncontractibility of the vertical and horizontal dimensions of the good. Without this assumption, the regulatory problem would-in a world of perfect information-be somewhat trivial. However, for hardto-define goods like medical care and schooling, nonverifiability of the vertical and horizontal dimensions is typically an intrinsic feature. In these cases, we show that optimal regulation must often negotiate a trade-off between encouraging the supply of higher-quality goods and reducing excessive horizontal differentiation in the market. This tradeoff arises because of the strategic interaction between competing firms' incentives for horizontal and vertical differentiation. The presence of this strategic interaction depends on the other key assumption of the model, namely that consumers' transportation costs are strictly convex, which implies that horizontal differentiation has a dampening effect on quality competition. Although this effect does not rely on the only plausible assumption about consumers' transportation costs, we nevertheless find it intuitively appealing.

\section{REFERENCES}

Anderson, S.P and M. Engers, 1994, "Spatial Competition with Price-Taking Firms," Economica, 61, 125-136.

Barros, P.P. and X. Martinez-Giralt, 2002, "Public and Private Provision of Health Care," Journal of Economics \& Management Strategy, 11, 109-133.

Bester, H., 1998, "Quality Uncertainty Mitigates Product Differentiation," RAND Journal of Economics, 29, 828-844.

Calem, P.S. and J.A. Rizzo, 1995, “Competition and Specialization in the Hospital Industry: An Application of Hotelling's Location Model," Southern Economic Journal, 61, 11821198.

D'Aspremont, C., Gabszewicz, J.J., and J.-F. Thisse, 1979, “On Hotelling's 'Stability in Competition,' Econometrica, 47, 1145-1150.

Economides, N., 1989, "Quality Variations and Maximal Variety Differentiation," Regional Science and Urban Economics, 19, 21-29.

— 1993, "Quality Variations in the Circular Model of Variety-Differentiated Products," Regional Science and Urban Economics, 23, 235-257.

Gabszewicz, J.J. and J.-F. Thisse, 1992, Location, in R.J. Aumann and S. Hart, eds., Handbook of Game Theory, Vol. 1, 281-304.

Gravelle, H., 1999, "Capitation Contracts: Access and Quality," Journal of Health Economics, $18,315-340$.

—-, and G. Masiero, 2000, Quality Incentives in a Regulated Market with Imperfect Information and Switching Costs: capitation in General Practice," Journal of Health Economics, 19, 1067-1088.

Hinloopen, J., 2002, "Price Regulation in a Spatial Duopoly with Possible Nonbuyers," The Annals of Regional Science, 36, 19-39. 
Hotelling, H., 1929, "Stability in Competition," Economic Journal, 39, 41-57.

Lyon, T.P., 1999, "Quality Competition, Insurance, and Consumer Choice in Health Care Markets," Journal of Economics \& Management Strategy, 8, 545-580.

Ma, C.A. and J.F. Burgess Jr., 1993, "Quality Competition, Welfare, and Regulation," Journal of Economics, 58(2), 153-173.

Nuscheler, R., 2003, "Physician Reimbursement, Time-Consistency and the Quality of Care," Journal of Institutional and Theoretical Economics, 159, 302-322.

Spence, M., 1975, "Monopoly, Quality and Regulation," Bell Journal of Economics, 6, 417429.

Wolinsky, A., 1997, “Regulation of Duopoly: Managed Competition vs. Regulated Monopolies," Journal of Economics \& Management Strategy, 6, 821-847. 